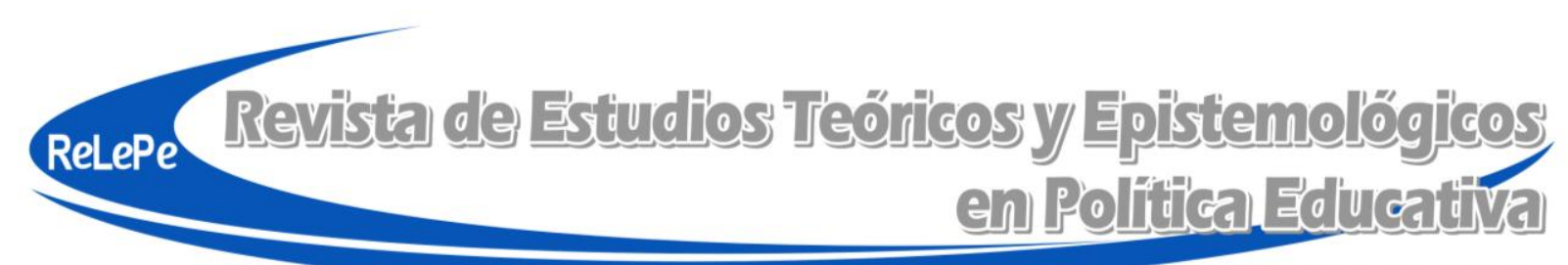

ISSN 2409-3696

DOI: $10.5212 /$ retepe.v.2.003

\title{
Distintos abordajes para el análisis de las políticas educativas: el caso de los programas que atienden el problema de las trayectorias escolares en la escuela secundaria
}

\author{
Gabriela Virginia Andretich \\ Universidad Nacional de Entre Ríos, Argentina \\ andretich.gabriela@gmail.com
}

\begin{abstract}
Resumen: Este artículo surge en el marco de una investigación (2013-2015) en la que se estudiaron problemas educativos históricos no resueltos de la escuela secundaria, como la repitencia, el abandono, la sobreedad y la deserción; todos ellos enmarcados en la temática de las trayectorias escolares. En base al aporte de distintos referentes teóricos que fueron surgiendo del proceso mismo de un diseño emergente de investigación, se analizaron distintas formas de abordaje de las políticas públicas haciendo foco en la idea de proceso y de complejidad de las mismas. Se presentan en este texto dos perspectivas desde donde se puede encarar el estudio de las políticas educativas: la mirada desde la producción, la circulación y el consumo como proceso comunicacional, y el ciclo de las políticas educativas.
\end{abstract}

Palabras clave: Políticas Educativas. Trayectorias Escolares. Escuela Secundaria.

Diferentes abordagens para a análise das políticas educacionais: o caso dos programas que abordam o problema das trajetórias escolares no ensino secundário

Resumo: Este artigo surge no contexto de uma investigação (2013-2015) em que foram estudados problemas históricos não solucionados do ensino secundário (Ensino Médio), como a repetência, o abandono, alunos com idade acima da esperada e a desistência; todos eles inseridos na temática das trajetórias escolares. Com base na contribuição de diferentes referenciais teóricos que foram surgindo do próprio processo de um projeto de pesquisa emergente, foram analisadas diferentes formas de abordagem das políticas públicas enfocando na ideia de processo e complexidade das mesmas. São apresentadas neste texto duas perspectivas a partir das quais pode-se confrontar o estudo das políticas educacionais: a visão desde a produção, a circulação e o consumo como processo de comunicação e o ciclo das políticas educacionais.

Palavras-chave: Políticas Educacionais. Trajetórias Escolares. Ensino Médio.

\section{Different approaches for the analysis of educational policies: the case of programs that address} the problem of school trajectories in the secondary school

\begin{abstract}
This article arises from a research project conducted from 2013 to 2015, in which historical educational unsolved matters from high school were studied, such as repetition, drop-out and overage; all of which belongs to the topic of school trajectories. According to the input of different theoretical references that emerged from the process of a rising design of investigation, different ways to approach the public politics focusing on the idea of process and complexity were analyzed. Two perspectives are presented in this text, from which the educational politics can be addressed: the view of production, circulation and consumption as a communicational process, and the cycle of educational politics.
\end{abstract}

Keywords: Educational Policies. School Trajectories. Secondary School. 


\section{Introducción}

Este artículo surge en el marco de una investigación (2013-2015) en la que se estudiaron problemas educativos históricos no resueltos de la escuela secundaria, como la repitencia, el abandono, la sobreedad y la deserción; todos ellos enmarcados en la temática de las trayectorias escolares. En base al aporte de distintos referentes teóricos que fueron surgiendo del proceso mismo de un diseño emergente de investigación, se analizaron distintas formas de abordaje de las políticas públicas haciendo foco en la idea de proceso y de complejidad de las mismas. Se presentan en este texto dos perspectivas desde donde se puede encarar el estudio de las políticas educativas: la mirada desde la producción, la circulación y el consumo como proceso comunicacional, y el circuito de las políticas educativas. El desarrollo del artículo incluye una breve aclaración sobre el objeto de estudio de la investigación de referencia, luego la presentación de los abordajes para el estudio de las políticas educativas y, por último, avances de lo analizado acerca de las trayectorias escolares en la escuela secundaria actual en dos provincias argentinas.

\section{Algunas aclaraciones sobre las trayectorias escolares}

En las ciencias sociales siempre estuvo presente el análisis de trayectorias (sociales, laborales, de formación, etc.) a través del estudio de las historias de vida o biografías, pero en los últimos tiempos cobró significativa importancia desde nuevos desafíos, tanto políticos a partir de la obligatoriedad del nivel medio, como sociales e institucionales. Las trayectorias son los recorridos, los itinerarios trazados por los alumnos del sistema escolar; éstos llevan consigo y van poniendo de manifiesto diversas formas de actuar, sentidos, valores y expectativas que constituyen una forma de concebir al mundo. Éstas a la vez se desarrollan en una matriz de diversas relaciones objetivas que pueden pensarse y explicarse recurriendo a una analogía: la de pensar el recorrido del río, pero teniendo en cuenta la estructura de la red fluvial en su conjunto.

Al tiempo que la escuela secundaria se fue masificando en toda Latinoamérica -aunque no se pueda aún hablar de universalización-, resultó complejo resolver la atención de las desigualdades educativas traducidas en fracaso escolar, repitencia, sobreedad, abandono, una formación de calidad cuestionada, desinterés y apatía en alumnos y docentes, trayectorias escolares no encauzadas al decir de Terigi (2010), entre otros. En general, estos problemas se concentran especialmente en los sectores más empobrecidos. Tal como sostiene Dussel (2009), los procesos de selección y exclusión social hoy se producen al interior de las instituciones en combinación con situaciones sociales y condiciones institucionales precarias.

En Argentina, donde los porcentajes de cobertura son relativamente buenos ${ }^{1}$, es menester apuntar a una total democratización cualitativa de la escuela secundaria que no implica solamente garantizar el acceso y la contención sino también la permanencia en el sentido de avance en el proceso educativo según los niveles definidos por cada sistema educativo y el egreso de los mismos. La democratización cualitativa tiene que ver con lo que tradicionalmente se enuncia como la "calidad" de la educación, concepto muy controvertido que puede interpretarse como: "...fundamentalmente vinculado con el desafío de garantizar que los alumnos puedan tener acceso al conocimiento definido como relevante para cada uno de los tramos de la educación..." (Poggi en SITEAL, 2013, p. 3). En Argentina, esta democratización se ve fuertemente afectada como consecuencia de la repitencia, la sobreedad consecuente y los abandonos temporarios; solamente la mitad de los alumnos que ingresan al secundario con la edad teórica adecuada llegan al último año de estudio en el tiempo estipulado.

${ }^{1}$ La tasa neta de escolarización secundaria llegaba al 52,7\% en 1993, alcanzó el 85,7\% en el 2003 y un 84,4\% en el 2011 (Kessler, 2014). 
Los problemas de abandono, deserción, repitencia, sobreedad, ausentismo son denominados, en su conjunto trayectorias escolares. Se observa en alumnos que su paso por la escuela secundaria conforma itinerarios frecuentes o probables -que coinciden con las trayectorias esperadas formalmente-, pero otras distan de ellas, es decir que el recorrido por la escuela conforma trayectorias diferentes y poco lineales. Para explicar esta situación, Terigi (2007) sostiene que las trayectorias pueden ser teóricas o reales. Las trayectorias reales son lo que efectivamente pasa en las escuelas. Coincidiendo con esta autora, es conveniente nombrar lo que ocurre en el cotidiano escolar como trayectorias escolares encauzadas y no encauzadas (Terigi 2007); estas últimas implican el desajuste o desacople de las trayectorias reales respecto a las teóricas.

En relación al problema de las trayectorias escolares no encauzadas, en términos generales se observa en Argentina un aumento de la repitencia en todos los años de estudio (con picos de concentración en los dos primeros años de la escuela secundaria ${ }^{2}$ ); un incremento del abandono de la escolaridad sobre todo en los primeros grados de la escuela secundaria y una acentuación en la cantidad de alumnos con sobreedad. Hay además una baja en la promoción en todos los grados (Duro y Perazza, 2012).

En este nuevo contexto adquieren relevancia, tanto para investigadores como para los responsables ministeriales, las trayectorias escolares de los jóvenes de escuelas secundarias. La atención de esta y otra cuestiones, en su ciclo vital, implica estructurar acciones que se encaminen a su resolución o desaparición como asunto socialmente problematizado. La toma de posición que adopta un Estado producirá una orientación que, a modo de norma, condicionará el futuro del proceso social que se pretende modificar o transformar. Las posiciones tomadas en los ámbitos estatales se configuran al interior de la arena política. Es preciso conocer este ámbito dado que marca el modo negociado o conflictivo que poseen las decisiones o tomas de posición del Estado con relación a cierta cuestión como es el caso de las trayectorias escolares.

Desde el ámbito universitario y con el ánimo de generar información relevante que llegue a los hacedores de políticas, planteamos una investigación denominada Trayectorias escolares de la Escuela Media. Macro y microanálisis situacional en las provincias de Santa Fe y Entre Ríos. ${ }^{3}$. Con ella nos propusimos tres fases interrelacionadas con los siguientes objetivos: 1) Realizar un análisis situacional sobre las trayectorias escolares en los primeros años de la escuela secundaria de las provincias de Santa Fe y Entre Ríos. 2) Analizar las políticas educativas nacionales y provinciales para el nivel secundario sobre las trayectorias escolares y 3) Adentrarnos en perspectiva de los actores desde las experiencias escolares institucionales que apuntan al tratamiento del problema de las trayectorias escolares de los alumnos del Ciclo Básico de la escuela secundaria.

\section{El estudio de las políticas educativas}

El campo filosófico pone a la luz las discusiones acerca de las ideas sobre la política y las políticas. Se puede considerar que la política refiere de manera indeterminada a las relaciones de poder que se juegan en una sociedad. Por su parte, las politicas suponen diferentes estrategias que orientan la toma de decisiones y la consecuente acción requerida para atender los problemas

\footnotetext{
2 Durante el periodo de 1998 a 2010 la proporción de estudiantes repitientes es mayor en los primeros años del secundario que en el ciclo orientado. Mientras que en este último el porcentaje de repitientes alcanzó en el año 2010 al 7,3\% de los estudiantes, en el ciclo básico esta cifra fue ligeramente superior al 12\%. Esta situación equivale aproximadamente 38.000 repitientes más en el ciclo orientado y a 109.000 en el ciclo básico en 2010 respecto a 1998. (UNICEF).

3 Se trata del proyecto de investigación llevado a cabo entre 2013 y 2015. Universidad Nacional de Entre Ríos. Resolución CD 286/12. Directora: Dra. Gabriela Andretich, Codirectora; Mg. Virginia Kummer.
} 
sociales. En otras palabras, operacionalizan modos de ocuparse de los problemas públicos en un escenario histórico, socioeconómico, político y cultural particular (Chiroleu e Iazzetta, 2009).

La investigación sobre trayectorias escolares (2013-2015) se propuso ya en el diseño hacer una reflexión integral de las políticas educativas. Este objetivo partió de una revisión crítica sobre las pocas investigaciones existentes en Argentina centradas en análisis de políticas educativas del período post-reforma educativa de los ' 90 . Además de esta carencia, preocupaba al equipo que en los pocos estudios que había sobre las cuantiosas políticas públicas sancionadas durante los gobiernos kirchneristas ${ }^{4}$, primaban extractos estadísticos sobre resultados cuantitativos. Se decidió entonces cuestionar quién pensó las políticas y en qué contextos, qué actores sociales las implementaron, dónde y cómo; quiénes las recibieron, cómo las interpretaron y significaron y qué se obtuvo con esas políticas tanto en lo micro como en la macropolítica.

Para el análisis de la complejidad procesual de las políticas de atención de las trayectorias educativas, el grupo de investigación retomó el concepto de momento en un sentido matusiano desde donde este indica instancia, ocasión, circunstancia o coyuntura por la que atraviesa un proceso continuo que no tiene comienzo ni término definido; el paso por un momento determinado es sólo el dominio transitorio de dicho momento sobre los otros que siempre están presentes (Matus, 1990). En las políticas, por ejemplo, los momentos (de construcción, redacción, implementación, resultados) se encadenan y cierran circuitos repetitivos para ayudarse mutuamente y culminar cada vez en uno distinto de ellos. Ningún momento es primero que otros. Este punto de partida da cuenta de la integralidad de un proceso que contiene distintos componentes que no se dan necesariamente de forma lineal o secuencial, no obstante, es imperioso abarcar con la mirada a todos ellos si se desea conocer en profundidad el objeto de estudio. Es así que se rescata la importancia de analizar las políticas desde el momento en que se las imagina hasta el estudio de la magnitud de aquello que logran -o no- las mismas.

Para investigar el proceso de toma de decisiones políticas en relación a las trayectorias escolares y su puesta en marcha -teniendo presente el carácter espiralado y no lineal descrito en el párrafo anterior- la investigación de referencia consideró dos modos de abordaje: el análisis de procesos comunicacionales desde categorías de la visión clásica del marxismo sobre la economía: producción, circulación y uso; más avanzado el trabajo y producto del intercambio con otros investigadores, el equipo incorporó la perspectiva del Ciclo de las políticas educativas de Stephen Ball.

\section{La mirada desde la producción, la circulación y el consumo de las políticas}

Las categorías de producción, circulación y uso o consumo son sostenidas como atinentes al ciclo de producción y circulación de los bienes que los analistas culturales como García Canclini retoman de la perspectiva económica del marxismo y las resignifican en el plano teórico para los estudios culturales y comunicacionales. A pesar de que la utilización de estos ejes conceptuales es reiterada en distintas áreas del conocimiento en las Ciencias Humanas y Sociales (más prolífera en los años '80) no es muy común encontrar fundamentación al respecto. Gracias a la vinculación del equipo de investigación con la carrera de Comunicación Social se obtuvieron referencias del material "Codificar y decodificar" de Stuart Hall (1980) y de la traducción del texto original al castellano hecha por Silvia Delfino, docente de esa carrera.

\footnotetext{
${ }^{4}$ Refiere a dos períodos: el primero durante la presidencia de Néstor Kirchner (2003-2007), caracterizada por transformaciones importantes a nivel de la legislación con muy pocos avances en términos de políticas concretas que garanticen su efectivización. El segundo período, incluye las decisiones en curso de los dos gobiernos de Cristina Fernández de Kirchner (2007-2011, 2011-2015), en el que se observan algunos avances en las políticas destinadas a la inclusión social. Puede ampliarse esta información en Feldfeber y Gluz (2011).
} 
El texto de Hall (1980) explicita los cambios sustanciales en la forma de interpretar el proceso comunicativo. Según este autor, antes de la década de 1980, la investigación en comunicación de masas conceptualizó ese proceso en términos de circuito de circulación (modelo Emisor/Mensaje/Receptor). Esta interpretación ha sido criticada y superada por otra que toma como base el esqueleto conceptual de la producción material descripta en los Manuscritos y en El Capital de Marx donde se entiende al proceso comunicativo “...en términos de una estructura producida y sostenida a través de la articulación de momentos relacionados pero distintivos Producción, Circulación, Distribución/Consumo, Reproducción...” (Hall, 1980, p. 1). Esta mirada interpreta al proceso como una estructura compleja dominante ${ }^{5}$, "sostenida a través de la articulación de prácticas conectadas, cada una de las cuales, retiene sin embargo, su carácter distintivo y tiene su modalidad específica propia, sus propias formas y condiciones de existencia" (Hall, 1980, p. 1); es decir, como un pasaje de formas. Para explicitar lo de estructuras dominantes Hall dice que las diferentes dimensiones de la vida en la que los sujetos se desarrollan socialmente se conforman según "una jerarquía de dominios en significados dominantes o preferentes" de tal forma que

...los eventos nuevos, problemáticos o conflictivos que quiebran nuestras expectativas o nuestras construcciones de sentido común, deben ser asignados a sus dominios discursivos antes de que puedan "tener sentido". El modo más común de ubicar en el "mapa" estos hechos es asignar lo nuevo a algún dominio de los existentes en el "mapa de la realidad social problemática. (Hall, 1980, p. 6)

Hall explica que las prácticas comunicativas tienen por objeto la producción de un mensaje o "vehículo de significados"; éstos se organizan de un modo específico bajo la forma de signos-vehículos a través de la puesta en funcionamiento de códigos dentro de la cadena sintagmática de un discurso. Aunque la transmisión y recepción requieren soporte material, Hall sostiene que se debe reconocer que la forma simbólica del mensaje tiene una posición privilegiada en el intercambio comunicativo y que los momentos de codificar y de-codificar son relativamente autónomos en relación al proceso comunicativo como un todo (Hall, en Martín Cabello, 2008, p. $8)$.

El mensaje se inicia a instancias de la producción donde las estructuras materiales, la materia prima de transforman en discurso. "En cierto momento, el mensaje debe ser elaborado en forma de discurso y, posteriormente, el discurso debe ser decodificado para ser percibido como mensaje" (Martín Cabello, 2008, p. 41), es decir, decodificado o recepcionado. "El consumo, o la recepción del mensaje constituye también un momento del proceso de producción en su sentido más amplio, a pesar de ser el último es el predominante, porque es el punto de partida de la efectivización del mensaje" (Hall, 1980, p. 2).

El valor que tiene esta aproximación según Hall es que aunque cada fase - que cumple funciones específicas- puede interrumpir el proceso, está articulada al resto de los momentos, esto hace que cada uno de ellos sea indispensable en el circuito completo de comunicación. Otro elemento interesante para rescatar de Hall, además del proceso recién explicitado, es que su perspectiva ayuda a no limitar los análisis -de políticas públicas, por ejemplo- sólo en función de las líneas guías que emergen de los análisis de contenido. La aplicación de este paradigma proveniente de los estudios culturales y comunicacionales transformó la comprensión del viejo

\footnotetext{
${ }^{5} \mathrm{Al}$ hablar de significaciones dominantes, Hall dice "que no estamos hablando de un lado del proceso que gobierna cómo los hechos serán significados. Consiste en el "trabajo" necesario para reforzar, ganar plausibilidad y dirigir como legítima la decodificación de un evento dentro del límite de definiciones dominantes en las cuales ha sido connotativamente significado" (Hall, 1980, p. 7).
} 
término "contenido" de los medios de comunicación ${ }^{6}$ así como también cambió la comprensión de la recepción de la audiencia, "lectura" y respuesta.

En la investigación de referencia, la propuesta de Hall fue resignificada para analizar el proceso de las políticas que atienden las trayectorias escolares. Desde esta perspectiva se pudo pensar el proceso que sigue una política educativa.

En el análisis de las políticas educativas puede comenzar por la formulación incluido todo lo que requiere producirla: las estructuras institucionales de gobierno con sus prácticas y redes de producción, sus relaciones poder e infraestructura. La producción, aquí, implica la construcción del mensaje. En un sentido entonces, el circuito comienza en su aspecto "discursivo". Este está estructurado a través de significados e ideas: qué problema se intenta resolver y cómo es analizado éste desde distintos actores sociales, qué otras formaciones discursivas dentro de estructuras políticas y socio-culturales más amplias hay que contemplar, desde qué fundamento ideológico-políticos se lo interpreta y qué mecanismos jurídicos se necesitan para su aprobación, definiciones y creencias acerca de la comunidad educativa.

Ahora bien, las relaciones institucionales y sociales de producción de una política deben pasar por las reglas discursivas del lenguaje para que su producto se concrete. Esto inicia un momento diferenciado posterior, en el cual las reglas formales el discurso y de lenguaje están en función dominante.

Antes de que el mensaje (la propuesta, ley, etc) pueda tener un "efecto", resolver la cuestión de las trayectorias en escuela media -por ejemplo-, debe primero ser apropiado en tanto discurso significativo y estar significativamente codificado. Es este conjunto de significados codificados el que luego "tiene un efecto, influye, entretiene, instruye o persuade, con consecuencias de comportamiento, perceptuales, cognitivas, emocionales, ideológicas muy complejas" (Hall, 1980, p. 3).

En el momento de la producción puede considerarse que se arma una política empleando un código y produciendo un mensaje; en otro momento el mensaje a través de la decodificación que de él se haga en los organismos intermedios y en las escuelas, se emite dentro de la estructura de las prácticas sociales. Esta re-entrada en las prácticas institucionales cotidianas, donde se receptan las políticas, no puede ser entendida en términos conductistas.

Para explicitar esta advertencia, Hall sostiene que "los procesos típicos identificados en la investigación positivista como elementos aislados -efectos, usos, gratificación-, están ellos mismos encuadrados en estructuras de entendimiento, a la vez que son producidos por relaciones sociales y económicas" (Hall, en Martín Cabello, p. 3). Estas últimas son las encargadas de efectivizar la recepción final de los contenidos de modo que éstos sean transpuestos en práctica o conciencia adquiriendo valor de uso social o efectividad política.

A partir de estas consideraciones básicas y en función del interés por analizar el proceso comunicacional de las políticas educativas sobre trayectorias escolares en dos provincias argentinas, el equipo de investigación seleccionó y reconceptualizó las categorías que se explican en los párrafos siguientes.

\footnotetext{
6 "En cualquiera de los extremos de la cadena comunicativa el uso del paradigma semiótico promete disipar el behaviourismo que ha entorpecido la investigación en medios masivos por tanto tiempo, especialmente en esta aproximación al contenido. Aunque sepamos que el programa de televisión no es un input de conducta, ha sido casi imposible para los investigadores tradicionales conceptualizar el proceso comunicativo sin patinar en una u otra variante del behaviourismo de corto vuelo" (Hall, 1980, p.4).
} 
La producción es la primera de las categorías retomadas y refiere a las condiciones políticoeconómicas desde dónde se genera la política. Usando la analogía de El Capital, éste es un proceso de trabajo en el modo discursivo. Es el contexto esencial para ubicar cada discurso/propuesta/plan. Serían las circunstancias históricas que condicionan un modelo social y económico donde se enmarca la ley/norma. Permite situar los hechos en el macro-contexto (más amplio, desde la reglas de última instancia), los niveles intermedios (una provincia por ejemplo) y el micro-contexto (una organización escolar).

Pensar en la producción implica partir de los contextos donde se inscribe el material de análisis, es decir, de su estructura de producción o de recepción comunicativa, social y culturalmente integrada: descripción de las características de las situaciones, entornos y contextos implicados en su producción y recepción (desde los históricos a los personales, desde los públicos a los privados), también la descripción de la estructura sociológica y psicológica que rige la conducta de los individuos, grupos o instituciones emisoras y receptoras en los procesos de comunicación que dieron origen a esos productos.

Las preguntas formuladas por el equipo para guiar la indagación en relación a la producción son:

- ¿por qué surge la política/norma? ¿en qué contexto político, social, económico?

- ¿quién la escribe? ¿con qué intenciones? ¿quiénes participa para hacerla?

- ¿quiénes discuten sobre el tema y qué dicen? ¿cómo resultan esas posturas en el texto de la ley/norma/programa?

- ¿cuál es el nivel de centralización/descentralización desde donde se la propone/escribe?

- ¿cómo se la da a conocer?

- ¿cuál es el grado y los modos de implementación que se prevén?

Otra de las categorías centrales retomadas de Hall es la de circulación: esta implica el momento en que el producto circula y se pone en relación. No ha sido demasiado abordado por los estudios sobre políticas públicas pero es, sin embargo, crucial para entender por qué muchas veces las propuestas políticas no se concretan o lo hacen de modo muy distinto al previsto. Constituye una bisagra entre lo que se escribió y lo que sucede en la cotidianeidad de las escuelas y marca los cambios en relación a lo prescripto.

Las preguntas formuladas para esta categoría son:

- ¿quiénes implementaron el programa/proyecto?

- ¿ ¿con qué grado de participación? ¿con qué indicaciones/directiva?

- ¿dónde se lo/la implementa? ¿con qué estrategias/mecanismos?

- ¿quiénes fueron los beneficiarios?

- ¿qué cambios sufrió desde la elaboración?

¿por qué?

- ¿en qué contexto socio-económico-político se aplicó? ¿quiénes hicieron los cambios?

La categoría uso o consumo, como tercero de los términos retomados del proceso de comunicación alude a que no se reciben los mensajes/proyectos/planes de manera descontextualizada, y además los que reciben lo hacen con una competencia propia a fin de interpretarlo y utilizarlo, y sobre todo comprenderlo. En el caso de las políticas para las 
trayectorias escolares, quienes las consumen son las instituciones educativas y más específicamente, los docentes y alumnos.

En esta categoría se analiza a los beneficiarios de las políticas (quiénes reciben el proyecto/propuesta/actividades). Así como puede analizarse la audiencia, también los receptores de las políticas públicas pueden ser caracterizados según perfiles determinados por su nivel social, cultural y económico.

Las propuestas/proyectos/actividades generan efectos y es necesario conocerlos e interpretarlos, estos tienen mucho que ver con la estrategia discursiva, es decir, con la intervención de los receptores. Según el texto de Hall (1980), hay tres tipos de efectos: sobre la conducta, sobre las emociones y sentimientos y sobre el conocimiento: ideología, valores, pensamientos. Los efectos de las políticas se pueden evaluar cuantitativamente o cualitativamente.

Las preguntas que se elaboraron para guiar este nivel del análisis son:

- ¿los beneficiarios fueron los mismos para quien se pensó el proyecto ley?

- ¿cómo lo/la recibió la población beneficiaria?

- ¿qué impacto produjo en la zona de aplicación?

- Si hubo cambios durante el desarrollo ¿cómo afectaron?

- ¿qué evaluación se hizo del mismo? ¿quiénes participaron de la evaluación?

- ¿qué resultados mostró?

Es significativo el aporte la perspectiva de Hall (1980) para el estudio de las políticas y sobre todo para realizar el análisis del discurso incluido de las política educativa, porque si no se quiere limitar una investigación a seguir sólo aquellas líneas que emergen de los análisis de contenido, se debe reconocer que la forma discursiva del mensaje tiene una posición privilegiada en el intercambio comunicativo (desde el punto de vista de la circulación), y que los momentos de codificación y decodificación son momentos determinados a través de una "autonomía relativa" en relación con el proceso de comunicación como un todo. Un hecho histórico, una política, por ejemplo no puede, de este modo, ser transmitido en bruto. Cuando un hecho histórico es considerado un discurso, "está sujeto a todas las 'reglas' complejas formales a través de las cuales el lenguaje significa" (Hall, 1980) ${ }^{7}$. Para explicarlo en forma paradójica, Hall dice que el evento debe convertirse en una "historia/relato" antes de que pueda convertirse en un evento comunicativo.

\section{El ciclo de las políticas educativas}

Miranda (2011) reconoce la complejidad que supone el abordaje y la interpretación de los procesos sociales localizados, particularmente de las políticas educativas, en los escenarios que corren. En consonancia con esta mirada, la autora recupera de Ball el concepto de trayectoria de las políticas y la consecuente consideración de los distintos contextos para el estudio de las mismas.

\footnotetext{
7 'En ese momento las sub-reglas formales del discurso están en 'función dominante', sin, por supuesto, subordinar la existencia del evento histórico así significado, las relaciones sociales en las cuales las reglas trabajan o las consecuencias sociales o políticas del evento que ha sido significado de este modo. La 'forma mensaje' es la 'forma aparición' necesaria del evento en este pasaje entre la fuente y el receptor. De este modo la transposición dentro y fuera de la 'forma mensaje' (el modo de intercambio simbólico) no es un momento 'azaroso' que podamos olvidar o ignorar de acuerdo con nuestra conveniencia. La 'forma mensaje' es un momento determinado; aunque, a otro nivel, comprende los movimientos superficiales del sistema de comunicaciones y requiere, en otro nivel, ser integrado dentro de las relaciones sociales del proceso de comunicación como un todo, del cual él sólo forma parte" (Hall, 1980).
} 
Miranda (2011) plantea que las políticas se configuran en una trama de contextos interrelacionados, no lineales, que suponen modos de interpretar el mundo y de cambiar la manera de pensar lo que hacemos. Estos contextos se entienden como "arena de actividad social y discursiva a través de los cuales las políticas se mueven y, dentro de los cuales, las políticas son producidas, creadas y ejecutadas" (Miranda, 2011, p. 109). Ball (2002) sostiene que Ciclo de Políticas (ver Figura 1) es un método para investigar y teorizar sobre las políticas, por lo que propone un esquema flexible con herramientas sociológicas que puedan otorgar sentido a la política. El investigador inglés sostiene que se necesita una perspectiva combinada o pluralista, capaz de abordar el desorden, la confusión de las realidades que caracterizan cualquier proceso político. El Ciclo de las Políticas permite “... establecer uma ligação entre estas duas posições (Estado e processos micropolíticos ou macro e micro análises) pela formulação de um referencial teórico que incorpora ambas as dimensões...” (Mainardes, 2006, p. 56).

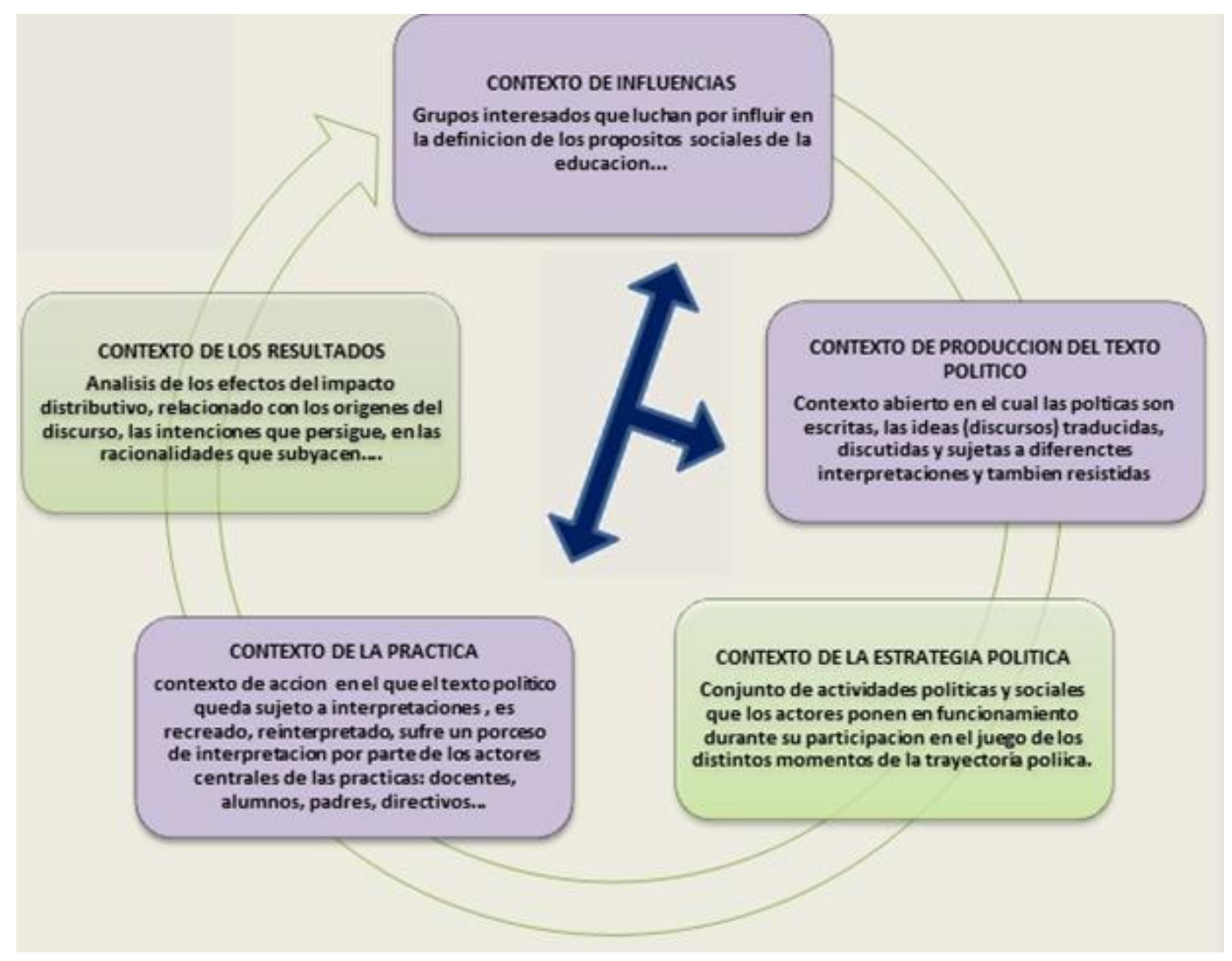

Figura 1. El ciclo de las políticas educativas

Fuente: elaboración propia en base a Miranda (2011) y Mainardes (2006)

El contexto de la influencia está relacionado con el momento de la construcción del discurso político, en donde se produce con mayor énfasis la disputa por la definición del sentido que adquirirán los principales conceptos de la política educativa. Para trabajar esta categoría en el análisis de las políticas públicas sobre trayectorias escolares en Argentina es pertinente recolectar toda la información relativa a las instancias previas a su generación en distintos ámbitos (políticos, sociales). Es importante el estudio de las discusiones de las comisiones que trataron, por ejemplo, la Ley General de Educación en las cámaras (diputados y senadores), en el Consejo General de Educación (ministros de educación de todas las jurisdicciones) y también el análisis de los documentos generados por otros actores sociales como los sindicatos docentes. Son también 
material de estudio los discursos de los funcionarios políticos y los medios oficiales de difusión de las normas/leyes que abordan la temática de las trayectorias.

El contexto de producción del texto político está referido al momento de la formulación escrita de la política, de su discusión, interpretación, reinterpretación y resistencia al interior de complejas relaciones de poder. Lo central desde el enfoque del ciclo de las políticas es mirar cómo el Estado interviene en la formulación de las mismas, pero también cómo estas se despliega más allá del control estatal por la acción de otros actores sociales.

Más allá de lo expresado por los estudiosos del ciclo de las políticas, si el propósito es comprender el encadenamiento de sentidos sobre decisiones recientes que pretenden atender y mejorar las condiciones de las trayectorias escolares de los alumnos del nivel secundario en su contexto de producción, hay que analizar un corpus de normativas nacionales y provinciales que se entrama en una red de relaciones más amplia (Laclau y Mouffe, 2004). En el afán de producir una mirada que articule una serie de discursos materializados en resoluciones emitidas por instituciones, el análisis de estos discursos se apoya en la construcción de enlaces con el deseo y el poder, los procedimientos que lo controlan y delimitan, las condiciones de producción y de utilización (Foucault, 1992). Se parte de la idea según la cual todo discurso es abierto, incompleto puesto que posee una significación relacional, generando procesos sociales de producción de sentido: “...en la práctica las políticas son poco claras, incoherentes, desordenadas, pero también poderosos recursos retóricos, modos de interpretar el mundo y de cambiar la manera en que pensamos sobre lo que hacemos" (Miranda, 2009, p. 107).

El contexto de la práctica está ligado al proceso de traducción que los docentes -actores centrales de la práctica educativa- hacen del texto político en su propósito de dotarlas de sentido (o cumplirlas), ya que el modo en que ellos piensan tiene profundas implicaciones en su puesta en acto. Ahora, las políticas no son simplemente implementadas en el contexto de práctica sino que son sujetas a interpretación y recreación (Bowe et al., 1992, citado por Mainardes, 2006 y por Kravetz, 2012).

Pensando en el último contexto presentado, mirar el nivel secundario desde las escuelas posibilita profundizar el conocimiento de procesos sociales marcados por las prácticas de diferentes actores -además del Estado-, cuyas capacidades de acumular fuerzas y recursos dirimen en la arena las estrategias de acción y los intereses sobre el asunto socialmente problematizado. En esta fase se indaga el acoplamiento que se establece entre las iniciativas y las directrices gubernamentales y las vivencias escolares cotidianas porque como sostiene Ball (2002), lo que sucede dentro de cada escuela en tanto resignificación de las políticas emanadas de distintas esferas gubernamentales está mediado por la vida cotidiana de las escuelas.

Las tres dimensiones mencionadas, conectadas por flechas en la Figura 1 son las básicas de la propuesta del Ciclo de las Políticas, mientras que las otras dos -secundarias en la interpretación de Ball- parecieran ser muy pertinentes para complementar el estudio de los cuantiosos programas/proyectos/propuestas para atención atender las trayectorias escolares en Argentina.

El contexto de la estrategia política incluye "la identificación de un conjunto de actividades sociales y políticas que serían necesarias para afrontar las desigualdades creadas o reproducidas por la política investigada" (Mainardes, 2006, p. 55). Retomando a Novick de Senén González y Villela Paz (2013), en este contexto hay que tener en cuenta distintos factores que afectan el proceso, como lo son los cambios y/o condicionamientos producidos en distintos entornos; cambios macrosociales, propios de la incertidumbre epocal, cambios en la arena política que se 
dan tanto en el espacio donde y cuando surge la ley o normativa, como en lo producido en los diversos espacios de aplicación, incluso en lo que ocurre en cada escuela.

El contexto de los resultados refiere a la necesidad de analizar los efectos de las políticas en tensión con los orígenes del discurso, sus intenciones y los cambios producidos sobre la desigualdad y las formas de injusticia educativa y social. Mainardes (2006) considera apropiado sostener la idea de que las políticas tienen resultados y logros, más que efectos y en este contexto, se preocupa por las cuestiones de la justicia, la igualdad y la libertad individual y. Desde esta lectura de la propuesta de Ball, las políticas debieran ser analizadas en términos de su impacto en relación a los indicadores de desigualdad social. Mainardes (2006) dice que Ball (2000) presenta aún una distinción entre efectos de primer orden y de segundo orden. Los efectos de primer orden hacen referencia a los cambios en las prácticas o en las estructuras y son evidentes en lugares específicos o en el sistema como un todo. Los efectos de segundo orden se refieren al impacto de esos cambios en las leyes de acceso social, oportunidad e injusticia social.

\section{Avances en el proceso de análisis de las políticas sobre trayectorias escolares en dos provincias argentinas}

Las dos perspectivas (Producción, Circulación y Uso, y Ciclo de las Políticas Educativas) se utilizaron de manera complementaria en el desarrollo de la investigación sobre trayectorias; ambas se consideraron como enfoques epistemetodológicos (Tello, 2013), es decir, como caminos de búsqueda de información e interpretación en el terreno en base a un corpus de teoría general y sustantiva.

La perspectiva crítica es la base epistemológica sustentada por el equipo de investigación; la misma parte de una desaprobación al paradigma epistemológico dominante basado en el discurso de la modernidad y se ubica -tal como sostiene Sousa Santos (2009)- en un postmodernismo de oposición $^{8}$. Esta postura se basa en una visión que concibe a la realidad en su carácter procesual, contingente, no lineal, como multiplicidad de temporalidades y como campo donde se juegan constantemente distintas relaciones de poder. Se sostiene una mirada transdiciplinaria, susceptible de dar cuenta de la incorporación de los fenómenos sociales dentro de las coordenadas que trazan las grandes líneas interpretativas. Evidentemente, el estudio de las políticas educativas no puede hacerse desde un lugar histórico incondicionado sino en la factibilidad de indagar en las formas históricas de construcción del presente y las potencialidades de hoy para pensar los horizontes futuros (Retamozo, 2006). Esto supone que el esfuerzo de investigación se ancla en la reconstrucción teórica a partir de lo concreto y que, en un proceso de abstracción, considera relaciones y posibles historicidades de los mecanismos de constitución de sujetos y subjetividades (Retamozo, 2006). En lo que hace a los procesos políticos, estos se entienden como multifacéticos y dialécticos por lo que es necesario su análisis en distintos niveles o planos: macro y microsocial.

\footnotetext{
8 "Esta caracterização, necessariamente incompleta, permite identificar as principais diferenças em relação à concepção de pós-modernismo de oposição que tenho vindo a defender. Em vez da renúncia a projectos colectivos, proponho a pluralidade de projectos colectivos articulados de modo não hierárquico por procedimentos de tradução que se substituem à formulação de uma teoria geral de transformação social. Em vez da celebração do fim da utopia, proponho utopias realistas, plurais e críticas. Em vez da renúncia à emancipação social, proponho a sua reinvenção. Em vez da melancolia, proponho o optimismo trágico. Em vez do relativismo, proponho a pluralidade e a construção de uma ética a partir de baixo. Em vez da desconstrução, proponho uma teoria crítica pós-moderna, profundamente auto-reflexiva, mas imune à obsessão de desconstruir a própria resistência que ela funda. Em vez do fim da política, proponho a criação de subjetividades transgressivas pela promoção da passagem da acção conformista à acção rebelde. Em vez do sincretismo acrítico, proponho a mestiçagem ou a hibridação com a consciência das relações de poder que nela intervêm, ou seja, com a investigação de quem híbrida quem, o quê, em que contextos e com que objetivos" (Sousa Santos, 2006, p. 29).
} 
Se parte, fundamentalmente, del pensamiento de Gramsci, que aporta elementos esenciales como la mirada relacional basada en las contradicciones sociales, la disparidad de intereses y el conflicto como elementos intrínsecos de las relaciones sociales. Se recupera el supuesto de la naturaleza política de la educación y la naturaleza pedagógica de la política.

A estas consideraciones acerca del desarrollo epistemológico se le suma la mirada latinoamericana que, según el portugués Sousa Santos, constituye la Epistemología del Sur. Para él implica una comprensión del mundo más amplia que la que brinda la perspectiva occidental. Una epistemología que, a diferencia de la moderna -cuya trayectoria parte de un punto de ignorancia, que Sousa Santos denomina caos, para llegar a otro de saber que llama orden (conocimiento comoregulación)-, tenga por punto de ignorancia el colonialismo y como punto de llegada la solidaridad (conocimiento como emancipación) (Sousa Santos, 2009).

A partir de la matriz epistemológica explicitada, se pueden presentar algunas consideraciones sobre las políticas que atienden la cuestión de las trayectorias escolares en la Argentina actual:

- En Argentina, en la década del '90 las políticas compensatorias emergieron como estrategia para disminuir las desigualdades sociales a través de la intervención estatal sobre las escuelas desfavorecidas. A partir del 2000 se desarrolló una visión crítica hacia ellas, invocando la necesidad de establecer criterios universales. Sin embargo, en el plano de las políticas educativas se mantuvieron estrategias específicas destinadas a los grupos más vulnerables. Hasta el momento, el abordaje político de las desigualdades educativas puso el acento en la redistribución, con el fin de "dar más a los que menos tienen", esta opción puede encuadrarse en lo que muchos denominan discriminación positiva.

- El discurso promovido por el Estado a través de la LEN (Ley Nacional de Educación, sancionada en el año 2006) busca dotar de sentidos a la obligatoriedad del nivel y configurar otros sentidos "al ir y al estar" en la escuela. Desde 2004 se comenzaron a elaborar documentos para la discusión desde el Consejo Federal de Educación (CFE), en acuerdo entre el ministerio nacional, las provincias y la ciudad de Buenos Aires. En lo que hace a las trayectorias escolares específicamente, el Artículo 32 de la LEN refiere particularmente a la Educación Secundaria y deposita en el CFE la responsabilidad de fijar disposiciones que enmarquen la producción normativa de las provincias en su rol de garantes del acompañamiento de la trayectoria escolar de los alumnos/as. Por otra parte, las políticas educativas sancionadas en el marco de esta ley nacional, se tensan con otras políticas de inclusión y regularización de las condiciones para el ingreso, la permanencia y el egreso de este nuevo tramo obligatorio.

- En la puesta en marcha de otras políticas nacionales que trascienden el campo educativo (“Asignación Universal por Hijo”, Decreto 6209/2009; "Programa de Respaldo a Estudiantes Argentinos - PROGRESAR", Decreto 84/2014; Ley de Protección Integral de Niños, Niñas y Adolescentes $\mathrm{N}^{\circ}$ 26061/2005) se deja ver un abordaje de la complejidad y la multidimensionalidad de los problemas públicos para incorporar, mantener o reinsertar a las/os niñas/os, adolescentes y jóvenes en el sistema educativo en cumplimiento de un derecho humano, lo que repercute y genera efectos en las instituciones educativas, fundamentalmente en el sector público.

- Si bien las políticas previas a la LEN estaban orientadas a mejorar las condiciones de tránsito de los adolescentes por la escuela secundaria, tenían foco en fragmentos parciales y aislados de una problemática: evaluación, concursos docentes, acuerdos marco, selección de contenidos, capacitaciones docentes, programas de finalización del secundario, entre otras; podría afirmarse que la intención política de la LEN viró hacia el modo en que había que organizar las acciones 
escolares para enfatizar el sentido de garantizar trayectorias escolares sobre la base del reconocimiento de la existencia de sujetos que tendrán diferentes modos de transitar la escolaridad.

- En los dos planes nacionales de Educación Obligatoria (2009 y 2012-2016) así como en las resoluciones $\mathrm{N}^{\circ} 79 / 09$ y 188/12 del CFE se expone la preocupación por garantizar las trayectorias escolares desde una perspectiva integral.

- La categoría trayectoria escolar es de reciente implementación en el discurso normativo mientras que desde el campo académico ya se venía afirmando la necesidad de pensar -a partir de ella- ciertas problemáticas educativas como repitencia, sobreedad, abandono, bajo rendimiento, inasistencias reiteradas (Terigi, 2007, 2010). Si bien estas problemáticas son históricas en el nivel y en el sistema educativo, la diferencia de mirarlas de manera integral radica en habilitar la toma de decisiones institucionales sobre la base de comprender la interacción entre los sujetos, considerar el contexto social de procedencia y el contexto escolar para proponer intervenciones con mayor peso institucional, concibiendo estos problemas a la luz de que la educación secundaria es un derecho.

- La variedad de políticas contempla la asignación de más recursos, más equipamiento, más cargos docentes, más horas de clase y/o más oportunidades para rendir los exámenes. Según distintas opiniones (Veleda, et. al, 2011), las políticas compensatorias actuales ofrecen más recursos a las escuelas más pobres, en algunos casos complementados con apoyo técnico y capacitación pero "... no cuestionaron los factores estructurales del propio sistema educativo que explican por qué los alumnos de sectores más postergados fracasan, aprenden menos y tienen más dificultades para construir un proyecto educativo y de vida" (Veleda, et.al.2011, pp. 60-61).

- En cuanto al desarrollo y continuidad de las políticas se encontraron muchos cambios en el desarrollo de las mismas entre los distintos años de su aplicación desde el nivel central y se hicieron visibles las disparidades entre los diversos signos políticos de las jurisdicciones provinciales. En la última década, en los discursos estatales se evidencian categorías que se reiteran en las resoluciones nacionales, tales como: inclusión, obligatoriedad, derecho a la educación, regularización de las trayectorias escolares, calidad, institucionalidad de la acción pedagógica, sentido de universalidad y/o universalización de la educación.

- La inclusión es un propósito que se gesta en distintos ámbitos sociales, es asumida políticamente por el gobierno nacional que la formula en términos de ley asociada a la obligatoriedad escolar. Entonces, es posible pensar que la obligatoriedad escolar resulta de la intención última de incluir en lo social, considerando que la inclusión educativa es la instancia intermedia que se concreta a través del ingreso, permanencia y egreso del sistema educativo, al menos en los niveles obligatorios.

- En el abordaje de las instancias de gobierno educativo provinciales, como fue el caso de la Dirección de Enseñanza Secundaria de una de las provincias objeto de estudio, se vislumbraron: esfuerzos personales -hasta mesiánicos o extenuantes en lo físico y mental- de quienes se hacen cargo de la puesta en práctica de los programas; la contratación de técnicos externos que se sumaron a las abarrotadas plantas estables de los ministerios; exiguo apoyo a las escuelas al momento de la implementación de los programas y escasas definiciones por parte de los funcionarios encargados de discutir, pautar y proponer líneas políticas que enmarquen los procesos educativos en su conjunto. Estos últimos se muestran, ante todo, como parte de una lucha de intereses políticos partidarios muy conflictiva que los mantiene cotidianamente ocupados en no perder espacios conquistados.

- Se hace notoria la dificultad de los espacios intermedios para extender los programas al pasar de una gestión a otra, aun siendo estas del mismo partido; esto podría deberse al poco registro de las acciones realizadas, la escasa previsión sobre la continuidad de los proyectos y el recambio permanente del personal técnico o de apoyo de cada grupo dirigente. 
- La provincia de Entre Ríos, particularmente, generó una serie de documentos orientadores sobre el tratamiento de las trayectorias escolares; sin embargo, entre los docentes se reconoce la dificultad de comprender claramente al interior de los mismos las relaciones posibles entre trayectorias escolares, obligatoriedad, institución-escuela, enseñanza y/o inclusión.

- La cuestión de las trayectorias escolares es reconocida en el ámbito escolar, se debate entre directivos y docentes y se analiza la normativa proveniente de los distintos niveles del sistema, pero los resultados en el conjunto de las escuelas de cada jurisdicción es muy dispar.

- En las escuelas que cuentan con propuestas instituciones para enfrentar el problema de las trayectorias escolares se puede ver básicamente la construcción de alternativas situadas. Las políticas educativas y sus consecuentes programas y proyectos son aprovechados por estas escuelas, pero sólo a los efectos de mejorar los recursos humanos y físicos para las acciones que ya tenían proyectadas. Muchas veces, los programas estatales vienen a poner un nombre a lo que ya venían haciendo.

- Para la mayoría de las escuelas, donde no hay planteos institucionales de atención del problema de las trayectorias, los programas significan una recarga de trabajo administrativo más que soluciones.

- Aunque algunas normativas enuncian posibilidades de cambiar los formatos de la escuela, las propuestas de intervención de las escuelas investigadas tienden a no transformar la estructura de tiempos y espacios en términos institucionales; sólo lo hacen con los grupos más desfavorecidos en el proceso de inclusión generando ámbitos paralelos de atención para el nivel secundario de la escolaridad.

A modo de cierre se puede expresar que este texto mostró el camino recorrido para el análisis de las trayectorias escolares en la escuela media vistas desde un país, Argentina, en un contexto de particular complejidad y cambio epocal, donde se visualizó que "...en la práctica las políticas son poco claras, incoherentes, desordenadas, pero también poderosos recursos retóricos, modos de interpretar el mundo y de cambiar la manera en que pensamos sobre lo que hacemos" (Miranda, 2011, p. 107). El estudio permitió reconocer los distintos "momentos" de las políticas educativas y aunque no todos fueron analizados con la misma profundidad, se pudo palpar la trama de discursos y acciones que se teje en cada uno de ellos, las distintas interpretaciones y las diferentes formas de concreción al interior de cada escuela.

\section{Referencias}

Andretich, G. (2014). "Proyecto de investigación Trayectorias escolares en la escuela media. Macro y microanálisis situacional de las provincias de Santa Fe y Entre Ríos". Primer informe de avance. Paraná, Argentina.

Ball, S. (2002). "Textos, discursos y trayectorias de la política: la teoría estratégica”. Páginas, v. 2, n. 3, pp. 19-33 (traducción Estela M. Miranda).

Chiroleu, A. e Iazzetta, O. (2009). "La política universitaria en la agenda de gobierno de Kirchner”. En: Marquina, M., Mazzola, C. y Soprano, G. (comps.). Políticas, instituciones y protagonistas de la universidad argentina. Buenos Aires: Prometeo.

Dussel, I. (2009). "Documento conceptual IV: Desafíos para la universalización de la enseñanza secundaria: aportes para la definición de políticas educativas". Reunión preparatoria para la sexta reunión de Ministros de Educación. Washington: Organización de los Estados Americanos. 
Duro, E., y Perazza, R. (2012). Acerca de la obligatoriedad en la escuela secundaria argentina. Análisis de la política nacional. Buenos Aires: Fondo de las Naciones Unidas para la Infancia.

Feldfeber, M., y Gluz, N. (2011). "Las políticas educativas en Argentina: herencias de los' 90, contradicciones y tendencias de "nuevo signo". Educação \& Sociedade, v. 32, n. 115, pp. 339-356.

Hall, S. (1980). "Codificar y Decodificar". Traducción Silvia Delfino. Disponible en: http://perio.unlp.edu.ar/catedras/system/files/hall._codificar-decodificar.pdf

Kravetz, S. (2012). "Formato escolar y obligatoriedad de la escuela secundaria. Reflexiones desde la perspectiva del ciclo de políticas educacionales". Ponencia en I Jornadas Latinoamericanas de Estudios Epistemológicos en Política Educativa. Buenos Aires.

Kessler, G. (2015). Controversias sobre la desigualdad: Argentina, 2003-2013. Buenos Aires: Fondo de Cultura Económica.

Laclau, E y Mouffe, C. (2004). Más allá de la positividad de lo social: antagonismo y hegemonía. Hegemonía y estrategia socialista. Radicalización de la democracia. Buenos Aires: Fondo de Cultura Económica.

Mainardes, J. (2006). "Abordagem do ciclo de políticas: uma contribuição para a análise de políticas educacionais”. Educação \& Sociedade, Campinas, v. 27, n. 94, pp. 47-69.

Martín Cabello, A. (2008). "Comunicación, cultura e ideología en la obra de Stuart Hall”. Revista Internacional de Sociologia, v. 66, n. 50, pp. 35-63.

Matus, C. (1990). Politica, planificación y gobierno. Caracas: Instituto Latinoamericano y del Caribe de Planificación Económica y Social y Fondo editorial Altadir.

Miranda, E. (2009). "Investigación sobre políticas educativas y procesos de integración académica regional”. Revista Políticas Educativas, v. 3, n. 1, pp. 18-32.

Miranda, E. (2011). "Una caja de herramientas para el análisis de las trayectorias de la política educativa. La perspectiva de los ciclos de la política". En: Miranda, E. y Newton, A. (eds.). Repensar la educación Pública. Aportes desde Argentina y Brasil. Córdoba: Centro de publicaciones de la Facultad de Humanidades de la Universidad Nacional de Córdoba.

Novick de Senén González, S. y Villela Paz, I. (2013). "Las políticas educativas como textos y como discursos. El enfoque de Stephen Ball”. En: Tello, C. (comp.). Epistemologias de la política educativa: posicionamientos, perspectivas y enfoques. Campinas: Mercado de Letras.

Retamozo, M. (2006). "Esbozos para una epistemología de los sujetos y movimientos sociales." Cinta de Moebio, Revista de Epistemología de Ciencias Sociales, n. 26, pp. 207-218.

Sistema de Información de Tendencias Educativas en América Latina (2013). "Conversación con Margarita Poggi. La agenda educativa latinoamericana". Disponible en http://www.siteal.iipe.unesco.org/debates/427/dialogo-con-margarita-poggi

Sousa Santos, B. (2006). A gramática do tempo: para uma nova cultura política. São Paulo: Cortez.

Sousa Santos, B. (2009). Una epistemología del sur. México: Siglo XXI.

Tello, C. (2013). Epistemologías de la política educativa: posicionamientos, perspectivas y enfoques. Campinas: Mercado de Letras. 
Terigi, F. (2007). ¿Qué hacer ante las desigualdades en la educación secundaria? Aportes de la experiencia latinoamericana. Buenos Aires: Santillana.

Terigi, F. (2010). "Las cronologías de aprendizaje: un concepto para pensar las historias escolares". Jornada de Apertura del ciclo lectivo 2010, Santa Rosa, Chubut.

Fondo de las Naciones Unidas para la Infancia y Asociación Civil Educación Para Todos (s/f). "Informe de oportunidades educativas en Argentina. 1998-2010". Disponible en https://www.unicef.org/argentina/spanish/Informe_nacional_-

_Las_oportunidades_educativas_en_Argentina_(1998_-_2010).pdf

Veleda, C; Rivas, A y Mezzadra, F. (2011). La construcción de la justicia educativa. Criterios de redistribución y reconocimiento para la educación argentina. Buenos Aires: CIPPEC y Fondo de las Naciones Unidas para la Infancia.

Artículo recibido en 16/03/2015

Artículo aceptado en 30/04/2016

\section{Gabriela Virginia Andretich}

Doctora en Ciencias Sociales, Universidad Nacional de Entre Ríos. Profesora Asociada e Investigadora de la Universidad Nacional de Entre Ríos, Argentina. 